cosmic and terrestrial physics. Continuous and highly refined observations on the sun have demonstrated the variable nature of the "solar constant." The so-called constants of heat conductivity, diffusion, viscosity, etc., pertaining to the ocean also vary with the conditions, though they are all thousands of times larger than the corresponding laboratory values.

For example, to determine the upwelling velocity in the southern California coastal region the author applied the classical equation ${ }^{1}$ for the diffusion of salts in a medium moving with the velocity $W$, to seasonal observations of ocean salinities at a series of depths, and obtained the value 40 in C.G.S. units for the diffusion constant $\mu^{2}$, while a Norwegian investigator, Jacobsen, obtained values varying from 0.3 to 11.4 for different regions of the sea near Denmark. The laboratory value for the diffusion coefficient of ocean salts in water is only .0000125 . The upwelling velocity in the southern California region was also determined by applying to serial ocean temperatures Fourier's equation for the flow of heat in a moving medium. The conductivity constant for this ocean region was found to be 30 , while the laboratory value of the coefficient of conductivity of sea-water is only .0012 .

The values of such constants found under the simple conditions of laboratory control are known to depend upon the temperature of the fluid. This is in turn an index of the complex molecular activity. In the ocean, the corresponding variable factor is the rate of interchange of small parts of the water in the ever present alternating convective circulation.

Complicated as those phenomena are, encouraging results have already come from quantitative studies, not only in oceanog-

1 Ocean temperatures, their relation to solar radiation: quantitative comparisons of certain empirical results with those deduced by principles and methods of mathematical physies by George $F$. McEwen, 1919, Semicentennial Publications of the University of California, 1868-1918, pp. 336-421, 19 figs. in text. raphy, but also in other geophysical investigations. GeORGE F. MoEweN

SCRIPPS INSTITUTION FOR

BIOLOGIOAL RESEARCH, UNIVERSTTY OF CALIFORNIA

\section{THE DIFFERENTIAL STAINING OF PLANT PATHOGEN AND HOST}

THE well-known difficulty experienced in staining to differentiate pathogen from host tissues in phytopathological studies needs no comment. In order to obviate this difficulty the writer has tried numerous combinations of stains and finally a method was hit upon which gives uniformly satisfactory results from the histological point of view. It is not intended for cytological studies although even for these there may be possibilities in the method.

The comparatively short time required to complete preparations, and the fact that students not yet expert in microtechnique can in most cases obtain good mounts, decided the question of publication.

\section{STAINS}

1. Magdala red. A 2 per cent. solution in 85 per cent alcohol.

2. Licht grün. A 2 per cent. solution in clove oil to which has been added a few drops of absolu'te alcohol.

\section{METHOD}

1. Dissolve paraffin in xylol and wash in absolute alcohol.

2. Wash in 95 per cent. and 85 per cent. alcohols.

3. Stain with Magdala red 5 to 10 minutes.

4. Remove surplus stain and wash in 95 per cent. alcohol.

5. Stain with Licht grün in clove oil for 1 to 3 minutes.

6. Wash in absolute alcohol, or in carbol-turpentine.

7. Clear in xylol and mount in Canada balsam.

The time factors may require slight modifications in some cases but a microscopic examination of the slide will enable the worker easily to determine the variation required. As a rule the staining with Licht grün is very rapid and if overstaining occurs the red becomes tinged with purple although this may 
not impair the visibility of the mycelium. In completed preparations the mycelium, spores, amoebæ or bacteroidal tissues are a brilliant red and host tissues green. This combination gives clear differentiation for visual microscopic study but for photomicrography the use of filters is necessary.

If sections are somewhat resistant to staining good results are obtained by first mordaunting them in a 1 per cent. solution of potassium permanganate in water for 2 to 5 minutes, afterwards washing in water and passing through graded alcohols to 85 per cent. The mordant must be freshly prepared as it will not keep.

Excellent preparations have been obtained with the following phytopathological material: Plasmodiophora brassicce, legume tubercles, Albugo candida, Phytophthora infestans, Plasmopara viticola, Exoascus pruni, Mycosphaerella rubina, Venturia inaequalis, Cronartium ribicola, Peridermium balsameum, Uromyces caryophyllinus, Puccinia malvacearum, Puccinia antirrhini, Puccinia graminis, etc.

It is hoped that others may find the method of some value.

\section{B. T. DiCKSON}

\section{Macdonald College, QUEBEC, CANADA}

\section{THE AMERICAN ASSOCIATION FOR THE ADVANCEMENT OF SCIENCE SECTION O-AGRICULTURE}

THE sessions of Section $O$, held in the Soldan High School, St. Louis, M.o., December 29 and 30th, 1919, were devoted to the diseussion of the general subject: "The Relation of the Use of Power and Labor-saving Machinery to Agricultural Progress." For the sake of effective presentation, the general subject was considered in four of its important relations, namely, the influence of farm machinery on production, labor and wages; the influence of power and machinery on social and physical conditions surrounding farm life; the application of power to save labor; and future needs and developments.

In discussing the first of these topies, Mr. Arnold P. Yerkes, of the International Harvester Company, referred to the evolution of farm machinery and pointed out that the first real farm machine was invented less than half a century ago. Such farm tools and implements as were used a hundred years ago were of the one-piece variety and could not be properly designated as marhines. They were very nearly identical with those that had been used by farmers for two or three thousand years. The invention of the reaper, in itself a rather simple machine, was quickly followed by other inventions represented by at least 100 distinct implements used on American farms at the present time. "During this period of invention and development of farm machines, American Agriculture has undergone a tremendous change. The old farming methods, which involved a great deal of hand labor, have given way for the most part to the use of machinery. An entirely new era of agriculture has been brought about and the new order has been made possible only through the invention of machines which reduced the amount of labor and the percentage of the population required to produce foodstuffs, thus enabling transportation and other industries to develop simultaneously with agriculture."

The invention and use of farm machinery has had at least two effects on labor. There has been a saving of labor by the increase in the efficiency of the individual and the consequent reduction in the number of men required to accomplish a given task. There has been, further, a substitution of animal and mechanical energy for human energy and the making of farm work less irksome and exhausting. For these reasons the employer of farm labor lays less stress than formerly on mere physical development and is willing to pay more for technical skill, initiative and manual expertness. "Incidentally these changes, brought about by the use of machinery, have resulted in a decided change in the type of farm hands upon American farms as whole. A few years ago immigrants who had had experience on the small farms in Europe made what were considered first-class farm hands, since they had a fair knowledge of a type of farming which did not differ materially from that found in this country. At that time many of the immigrants sought employment on farms in America and found it. But with the increased use of farm machinery this class of labor became less and less satisfactory because very few of the immigrants had any knowledge whatever of farm machinery, and, as many of them could not understand the English language, it was difficult to teach them. The practise of hiring these "green" immigrants therefore became less common." 